\title{
Hubungan Kualitas Tidur dengan Kapasitas Memori Kerja Siswa Sekolah Menengah Atas Islam Terpadu Iqra' Kota Bengkulu Tahun 2018
}

\author{
Nina Tabligha ${ }^{1}$, Andri Sudjatmoko ${ }^{2}$, Dessy Triana ${ }^{3}$ \\ ${ }^{1}$ Program Studi Kedokteran Fakultas Kedokteran dan IImu Kesehatan Universitas Bengkulu, \\ ${ }^{2}$ Bagian Kejiwaan RSUD Dr. M. Yunus Bengkulu, \\ ${ }^{3}$ Bagian ParasitologiFakultas Kedokterandan IImu Kesehatan Universitas Bengkulu
}

Latar Belakang: Tidur merupakan kebutuhan fisiologis dasar bagi setiap individu yang dapat memengaruhi kualitas serta keseimbangan hidup. Tidur memiliki fungsi salah satunya yaitu berpengaruh ke sistem saraf sehingga bisa berdampak terhadap memori dan kemampuan belajar. Tuntutan sekolah, kegiatan sosial setelah sekolah dan gaya hidup dapat menyita waktu tidur. Di Sumatera Utara, dari 287 pelajar dilaporkan 220 pelajar yang mengalami kualitas tidur yang buruk. Penelitian ini bertujuan untuk mengetahui adanya hubungan kualitas tidur dengan kapasitas memori kerja pada siswa SMA.

Metode: Penelitian ini menggunakan desain penelitian cross sectional. Penelitian dilakukan di SMAIT Iqra' Kota Bengkulu pada bulan Agustus 2018. Pemilihan sampel dilakukan berdasarkan simple random sampling. Instrumen yang digunakan dalam penelitian untuk menilai kualitas tidur yaitu kuesioner Pittsburgh Sleep Quality Index, sedangkan pengukuran kapasitas memori kerja menggunakan reading span test. Korelasi antara kedua variabel tersebut akan dianalisis mengggunakan uji Spearman.

Hasil: Total sampel penelitian yang dianalisis adalah 53 siswa, 18 siswa (34\%) memiliki kualitas tidur yang baik dan 35 siswa (66\%) memiliki kualitas tidur buruk. Hasil penelitian menunjukkan adanya korelasi yang bermakna antara kualitas tidur dengan kapasitas memori kerja dengan nilai $p=0,042, r$ $=0,281$.

Kesimpulan: Terdapat hubungan positif yang signifikan antara kualitas tidur dengan kapasitas memori kerja pada siswa SMAIT Iqra' Kota Bengkulu.

KataKunci: kualitas tidur, kapasitas memori kerja, siswa sekolah menengah atas.

\section{ABSTRACT}

\section{The Relationship between Quality of Sleep with Working Memory Capacity in Student at Integrated Islamic Senior High School Bengkulu 2018}

\author{
Nina Tabligha ${ }^{1}$, Andri Sudjatmoko ${ }^{2}$, Dessy Triana ${ }^{3}$ \\ ${ }^{1}$ Medical Program, Faculty of Medicine and Health Sciences, Bengkulu University, \\ ${ }^{2}$ Department of Psychiatric of Dr. M. Yunus Bengkulu Hospital, \\ ${ }^{3}$ Department of Parasitology Faculty of Medice and Health Sciences, University of Bengkulu
}

Background: Sleep is a basic physiological need for each individual. Sleep also has an important role in learning, decision making, critical thinking, and memory consolidation. Whereas school demands, social activities after school, and lifestyle can take up student's sleep time. In North Sumatra, from 287 students, there were 220 students who experienced poor sleep quality. This study aimed to determine the relationship between sleep quality and working memory capacity in high school students.

Methods: This study used a cross sectional study design. The study was conducted at SMAIT Iqra 'Kota Bengkulu in August 2018. The sample was taken based on simple random sampling technique. The instrument that used in the study to assess sleep quality is the Pittsburgh Sleep Quality Index questionnaire, while the measurement of working memory capacity is using reading span test. The correlation between the two variables will be analyzed using the Spearman test.

Results: The total analyzed sample was 53 students, and the result was 18 students (34\%) had good sleep quality and 35 students $(66 \%)$ had poor sleep quality. The results showed a significant correlation between sleep quality and working memory capacity with $p=0.042, r=0,281$.

Conclusion: There is a significant positive relationship between sleep quality and working memory capacity of students of SMAIT Iqra' Kota Bengkulu.

Keywords: sleep quality, working memory capacity, high school students. 


\section{PENDAHULUAN}

Tidur merupakan kebutuhan fisiologis dasar bagi setiap individu dalam mempertahankan kehidupannya secara fisik dan memengaruhi kualitas serta keseimbangan hidup. $^{1} \quad$ National $\quad$ Sleep Foundation (2015) menyebutkan bahwa durasi tidur yang direkomendasikan usia 14-17 tahun adalah berkisar 8-10 jam. ${ }^{2}$ Tuntutan sekolah, kegiatan sosial setelah sekolah dan gaya hidup dapat menyita waktu tidur. ${ }^{1}$ Tidur merupakan hal yang penting bagi manusia dikarenakan kualitas hidup manusia akan terganggu apabila kebutuhan tidurnya tidak tercukupi. Tidur juga memiliki peranan penting dalam proses belajar, pengambilan keputusan, berpikir kritis, dan konsolidasi memori. ${ }^{3}$

\section{Kemampuan kognitif seseorang}

dipengaruhi oleh kapasitas memori kerja. ${ }^{4}$

Murid dapat mengalami kesulitan dalam mengolah materi pelajaran, menerima informasi baru, dan mengikuti instruksi dalam pembelajaran akibat memiliki memori kerja yang rendah. ${ }^{5,6}$ Penelitian yang dilakukanpada
143 orang yang berusia 13-18tahun di

Adelaide

(Australia

Selatan),

menunjukkanadanyahubungan antara kehilangan tidur yang dialami remaja dengan kinerja memori kerja. Nilaispan testpada remaja yang mengalami tidur kurang dari 8 jam dalam sehari mendapatkan hasil yang lebih rendah dibandingkandenganremaja yang tidur 8-9 jam. ${ }^{7}$

Penelitian tentang Sleep Pattern and Problems among Chinese Adolescent yang dilakukan pada anak remaja di China menunjukkan hasil penelitian sebanyak 18,8\% mengalamikualitas tidur yang buruk, 26,2\% tidak merasa puas pada saat tidur, $16,1 \%$ mengalami insomnia, dan 17,9\%mengantuk pada siang hari, yang menyebabkan gangguan dalam konsentrasi dan proses belajar sehingga dapat memengaruhi hasil indeks prestasi belajar siswa. Hasil penelitian ini membuktikanbahwa kurang tidur dan kantuk pada siang hari lebih banyak terjadi pada siswa sekolah menengah atas dibandingkan dengan siswa yang masih berada di sekolah 
menengah pertama. ${ }^{8}$ Kualitas tidur siswa SMA berdasarkan hasil penelitian yang dilakukan pada siswa SMA Negeri 1 Tanjung Morawa dengan jumlah total sampel sebanyak 287 pelajar, dilaporkan 220 pelajar yang mengalami kualitas tidur yang buruk. $^{9}$ Penelitian tentang hubungan kualitas tidur dengan kapasitas memori kerja pada siswa sekolah menengah atas di Surakarta mendapatkan hasil yang menunjukkan adanya hubungan positif kuat yang bermakna antara kualitas tidur dan kapasitas memori kerja. ${ }^{10}$

Di Kota Bengkulu, SMAIT Iqra' merupakan salah satu sekolah menengah atas yang memiliki jadwal cukup padat. SMAIT Iqra' Kota Bengkulu memadukan antara kurikulum Pendidikan Nasional (KTSP 2013) dengan kurikulum khas Sekolah Islam Terpadu (SIT). Siswa SMAIT Iqra' Kota Bengkulu menerapkan jadwal pembelajaran dari hari Senin sampai dengan hari Jum'at dimulai dari pukul 07.15 s.d 15.30 WIB. Padatnya jadwal SMAIT Iqra' Kota Bengkulu dan didukung oleh beberapa penelitian yang telah dipaparkan di atas mengenai prevalensi kualitas tidur pada siswa SMA, maka dari itu peneliti merasa tertarik untuk melakukan penelitian guna mengetahui apakah ada hubungan kualitas tidur dengan kapasitas memori kerja pada siswa SMAIT Iqra' Kota Bengkulu.

\section{METODE}

$$
\text { Penelitian ini menggunakan studi }
$$

analitik observasional dengan desain penelitian cross-sectional. Populasi terjangkau pada penelitian ini adalah siswa SMAIT Iqra' Kota Bengkulu kelas XI (sebelas) usia 14-17 tahun. Sampel penelitian yang digunakan adalah populasi terjangkau yang memenuhi kriteria inklusi.

Kriteria inklusi pada penelitian ini adalah siswa SMAIT Iqra' Kota Bengkulu kelas XI (sebelas) usia 14-17 tahundan bersedia menjadi sampel penelitian. Kriteria eksklusi adalah siswa yang memiliki kebiasaan minum kopi $>3$ cangkir/hari, siswa yang merokok, siswa obesitas dengan hasil screening menunjukkan risiko tinggi untuk OSA, dan siswa yang sedang mengkonsumsi obat yang 
dapat mengganggu kualitas tidur. Sampel

diambil dengan cara semua subjek dipilih secara acak sederhana dan yang memenuhi kriteria inklusi akan dimasukkan ke dalampenelitian sampai jumlah sampel terpenuhi. Pengambilan sampel dari anggota populasi dilakukanpadasiswa-siswi kelas XI yang berusia 14-17 tahun secara acak dan anggota populasi dianggap sejenis atau homogen. Simple random sampling ini bisa dilakukan melalui undian. Sebelumnya, penelitiakan mendaftar semua anggota populasi yang bersedia melakukan penelitian dari setiap kelas yang berbeda. Kemudian sampel diambil secara acak dengan cara mengundi nama sampel yang dilakukan oleh peneliti hingga jumlah yang dibutuhkan tercapai.
Instrumen dan alat yang digunakan dalam penelitian ini yaitu, lembarkuesioner PSQI, slide Reading Span Test yang telahdistandardisasiberdasarkanpenelitian Oberauer et al. (2000) dan Friedman \& Miyake (2005), LCD proyektor, lembar jawaban Reading Span Test, dan alat tulis. ${ }^{11,12} \mathrm{Pada}$ penelitian ini analisis sebaran data diuji degan uji Kolmogorov-Smirnov.Analisis hubungan dua variabel dengan uji korelasi Spearman. Data diolah menggunakan softwareStatistical Program for Social Science (SPSS) for Windows version 24.

\section{HASIL}

\section{Karakteristik Subjek Penelitian}

Distribusi frekuensi karakteristik berupa usia dan jenis kelamin pada subjek penelitian dapat dilihat pada tabel 1 berikutini.

Tabel 1.DistribusiFrekuensiKarakteristikSubjekPenelitian $(n=53)$

\begin{tabular}{llll}
\hline Karakteristik & & $\mathrm{n}$ & $\%$ \\
\hline Usia & 14 tahun & - & - \\
& 15 tahun & 9 & 17,0 \\
& 16 tahun & 41 & 77,4 \\
\multirow{2}{*}{ Jenis Kelamin } & 17 tahun & 3 & 5,7 \\
& Perempuan & 36 & 67,9 \\
& Laki-laki & 17 & 32,1 \\
\hline
\end{tabular}


Tabel 1 menunjukkan bahwa rentang usia

subjek penelitian berkisar 15-17 tahun. Subjek

penelitian paling banyak berusia 16 tahun.

Tabel 1 juga menunjukkan bahwa jenis

\section{Frekuensi dan Rerata Kualitas TidurpadaSubjekPenelitian}

Tabel 2. Frekuensi dan Rerata Nilai Kualitas Tidur pada Subjek Penelitian

\begin{tabular}{lcc}
\hline VariabelPenelitian & $\mathbf{n ~ ( \% )}$ & HasilPengukuran \\
\hline KualitasTidur & & $6,00(3-13){ }^{* *}$ \\
$>5=$ Buruk & $35(66,0)$ & \\
$\leq 5=$ Baik & $18(34,0)$ & \\
\hline Keterangan: ${ }^{*}$ nilai dalam mean \pm SD, ${ }^{* *}$ nilai dalam median (min-max)
\end{tabular}

Tabel 2 menunjukkan siswa yang memiliki yang memiliki kualitas tidur yang baik (skor kualitas tidur yang buruk (skor PSQI >5) $P S Q I \leq 5)$ sebanyak 18 orang (34,0\%). berjumlah 35 orang $(66,0 \%)$, sedangkan siswa

\section{Frekuensi dan Rerata Kapasitas Memori Kerja pada Subjek Penelitian}

Tabel 3.Rerata Skor Kapasitas Memori Kerja Subjek Penelitian

\begin{tabular}{|c|c|}
\hline \multicolumn{2}{|c|}{ Hasil Pengukuran } \\
\hline Kapasitas Memori Kerja & $=4,775^{*}$ \\
\hline Keterangan : ${ }^{*}$ nilai dalam mean $\pm \mathrm{SD},{ }^{* *}$ nilai da & edian (min-max). \\
\hline Hasil penelitian berdasarkan tabel3 & Teknik analisis korelasi antara data \\
\hline didapatkan bahwa data karakteristik berupa & kategorik (kualitas tidur yang ditentukan \\
\hline kapasitas memori kerja sebaran data yang & berdasarkan skor PSQI) dan data numerik \\
\hline normal. Rerata skor kapasitas memori kerja & (kapasitas memori kerja) menggunakan uji \\
\hline subjek penelitian adalah $23,25 \pm 4,775$. & Spearman. Hasil uji Spearman antara kualitas \\
\hline Hubungan Kualitas Tidur dengan Kapasitas & tidur dan kapasitas memori kerja pada subjek \\
\hline Memori Kerja & penelitian dapat dilihat pada tabel 6 . \\
\hline
\end{tabular}


Tabel 4. HubunganKualitas Tidur dengan Kapasitas Memori Kerja

\begin{tabular}{lll}
\hline VariabelPenelitian & \multicolumn{2}{c}{ KapasitasMemoriKerja } \\
\hline KualitasTidur & $\mathrm{R}$ & 0,281 \\
& $\mathrm{P}$ & 0,042 \\
\hline
\end{tabular}

Tabel 4 menunjukkan bahwa terdapat korelasi yang bermakna antara kualitas tidur dengan kapasitas memori kerja dengan nilaisignifikan $0,042(p<0,05)$.Nilai korelasi Spearman antara dua variable yaitu 0.281 menunjukkan bahwa arah korelasi positif dengan kekuatan korelasi lemah.Hasil uji Spearman menjelaskan bahwa semakin baik kualitas tidur maka akan semakin tinggi skor kapasitas memori kerja.

PEMBAHASAN

\section{Karakteristik Subjek Penelitian}

Hasil penelitian menunjukkan bahwa subjek pada penelitian ini memiliki rentang usia 14-17 tahun, dengan persentase terbanyak pada usia 16 tahun yaitu sebanyak 41 orang $(77,4 \%)$. Hasil penelitian ini sejalan dengan penelitian yang tentang Sleep Hygiene Behavior among Balinese Adolescent dengan jumlah sampel 46 siswa kelas $\mathrm{X}$ dan $\mathrm{XI}$ di
Sekolah Tinggi PGRI Negara yang berusia 1619 tahun, dengan mayoritas sampel berusia 17 tahun (39.13\%). Penelitian ini menunjukkan bahwa remaja Bali sebagian besar mengalami gangguan dalam kualitas tidur atau perubahan jadwal tidur pada akhir pekan. ${ }^{13}$

Pada tahun 2011 sebanyak dua per tiga remaja mengalami kekurangan tidur. $^{14}$ Seiring bertambahnya usia, seseorang menjadi semakin sering mengalami gangguan tidur. Sekitar 30\% individu mengalami penurunan kualitas tidur. Penurunan kualitas tidur dapat mengganggu irama sirkadian yang mengakibatkan pola tidur yang tidak teratur. ${ }^{15}$ Padapenelitianinijugadidapatkansubjekp enelitian perempuan lebih banyak daripada laki-laki, yaitu $67,9 \%$ perempuan dan $32,1 \%$ laki-laki. Hasil penelitian ini sejalan dengan penelitian yang dilakukan pada 153 orang siswa kelas 2 SMA Negeri 10 Padang 
menunjukkan populasi sampel penelitian perempuan lebih banyak daripada laki laki.Sampel penelitian perempuan berjumlah 100 orang $(65,4 \%)$ sedangkan laki-laki berjumlah 53 orang $(34,6 \%){ }^{16}$

\section{Frekuensi Kualitas Tidur}

Hasil penelitian ini menunjukkan bahwa lebih banyak siswa yang mengalami kualitas tidur yang buruk dibandingkan dengan siswa yang mengalami kualitas tidur yang baik. Siswa dengan kualitas tidur yang baik ditandai oleh nilai skor PSQI $\leq 5$ sebanyak 18 orang (34,0\%), sedangkan siswa dengan kualitas tidur yang buruk dan memperoleh skor $>5$ sebanyak 35 siswa $(66,0 \%)$. Penelitian ini sejalan dengan penelitianyang dilakukan terhadap remaja yang menyimpulkan bahwa sebanyak $56,9 \%$ remaja memiliki kualitas tidur yang buruk, dan $43,1 \%$ memiliki kualitas tidur yang baik. ${ }^{17}$ Penelitianlain dengan sampel penelitian yaitu mahasiswa fakultas kedokteran dengan total sampel 107 mahasiswa yang menunjukkan hasil yaitu sebanyak 88 siswa $(82,2 \%)$ memiliki kualitas tidur buruk dan 19 mahasiswa (17,8 \%) sisanya memiliki kualitas tidur baik. ${ }^{18}$

Tidur merupakan kebutuhan dasar makhluk hidup yang berfungsi dalam memulihkan dan mengembalikan stamina tubuh ke kondisi yang optimal. ${ }^{19}$ Pada masa pubertas, seseorang akan lebih sulit untuk jatuh tertidur di malam hari dan bangun tidur lebih lama di pagi hari. $^{20}$ Remaja yang mengalami kekurangan tidur, kualitas tidur yang buruk, dan pola tidur yang tidak teratur dikaitkan dengan kantuk di siang hari, mood yang buruk, dan kinerja akademik yang buruk. Remaja sering tidak mendapatkan tidur yang cukup dikarenakan pada masa remaja awal, remaja mengalami pergeseran irama sirkadian. Kebanyakan remaja juga memiliki jadwal setelah sekolah. Aktivitas santai yang sering dilakukan remaja yaitu menonton televisi, menggunakan internet, dan bermain game juga dapat menunda waktu tidur. ${ }^{14}$

Pada penelitian ini, kualitas tidur yang buruk lebih banyak dialami oleh wanita daripada laki-laki. Hal ini sejalan dengan 
penelitian yang dilakukan pada 3.778 orang dewasa muda $(20,6 \pm 0,86$ tahun $)$ menunjukkanprevalensi pada wanita $(65,1 \%)$ yang mengalami kualitas tidur buruk lebih tinggi daripada laki-laki $(49,8 \%) .{ }^{21} \quad$ Hasil penelitian ini juga sejalan dengan penelitian yang dilakukan dengan sampel berusia 14-19 tahun di Brazil, jumlah sampel laki-laki 113 orang dan jumlah sampel perempuan 97 orang menjelaskan bahwa kualitas tidur yang buruk lebih sering terjadi di kalangan anak perempuan sebesar $76,3 \% .{ }^{22}$

Remaja perempuan adalah seseorang yang sering dilaporkan mengalami keluhan kualitas tidur yang buruk, hal ini dikaitkan dengan fakta terhadap perubahan hormonal yang terjadi selama masa remaja. Selama fase luteal dari siklus menstruasi, ketika tubuh perempuan mengalami perubahan, baik secara emosional dan fisik, perubahan estrogen dan progesteron memiliki pengaruh yangkuat pada siklus tidur-bangun. ${ }^{23}$ Perubahan ini dapat berpengaruh terhadap peningkatan latensi tidur dan penurunan signifikan dalam efisiensi kualitas tidur. ${ }^{24}$ Tidur memiliki banyak fungsi bagi kesehatan otak dan tubuh, diantaranya yaitu pertumbuhan selsel tubuh dan otot yang baru, perbaikansel-sel yang rusak(natural healing mechanism). Saattidur, $\quad$ terjadi $\quad$ proses konsolidasimemoriyaitu proses ingatan baru atau ingatan jangka pendek akan diintegrasikan kedalam memori jangka panjang. ${ }^{25}$ Dalam proses belajar, diperlukan adanya konsolidasi memori yang berperan dalam mengingat hasil pembelajaran.Remaja yang memiliki gangguan pola tidur dapat memengaruhi aktivitas sehari-harinya, terutama mengganggu proses belajar. ${ }^{26}$

\section{Frekuensi Kapasitas Memori Kerja}

Hasil penelitian ini menunjukkan bahwa skor RST dari 53 orang subjek penelitian, skor terendah yaitu 10 dan skor tertinggi yaitu 30 . Siswa yang mendapatkan skor 30 berjumlah 6 orang, 5 orang berusia 16 tahun dan 1 orang berusia 15 tahun. Hasil ini sejalan dengan teori Dehn (2008) menyebutkan bahwa kapasitas memori kerja mencapai kematangan 
pada usia 16 tahun ditandai dengan terjadinya

peningkatan akurasi, peningkatan kecepatan dalam mengolah informasi, mampu mengolah lebih banyak informasi dalam satu waktu, dapat menyelesaikan masalah yang lebih kompleks dan peningkatan kemampuan dalam menyusun strategi. ${ }^{27}$ Anak usia sekolah yang memiliki kapasitas memori kerja yang tinggi memiliki kemampuan dalam aktivitas mengingat, mampu berkonsentrasi, membaca, memaknai bacaan, berhitung, dan mengikuti instruksi, serta memiliki prestasi belajar yang baik. Anak yang memiliki kapasitas memori kerja yang rendah akan memiliki kapasitas penyimpanan infromasi dan kemampuan belajar yang terbatas dalam menangkap, menyimpan, memproses, memanipulasi, dan mengolah informasi. ${ }^{28,29}$

Pada penelitian ini didapatkan hasil skor RST terendah pada siswa perempuan adalah 10 sebanyak 1 orang, sedangkan skor tertinggi adalah 30 sebanyak 2 orang. Siswa laki-laki mendapatkan skor RST terendah yaitu 17 sebanyak 1 orang dan 4 orang siswa mendapatkan skor 30 . Terdapat perbedaaan antara memori kerja pada perempuan dan lakilaki. Hal ini diperkuat oleh penelitian telah menunjukkan bahwa dari penilaian terhadap perilaku, laki-laki menunjukkan memori kerja yang lebih besar dalam kemampuan matematika, mengingat suatu objek dan kemampuan spasial apabila dibandingkan dengan perempuan. ${ }^{30,31,32,33,34}$ Perempuan menghasilkan kemampuan verbal yang lebih baik (termasuk keterampilan menulis) daripada laki-laki. ${ }^{35,36}$

Hubungan Kualitas Tidur dengan Kapasitas Memori Kerja

Berdasarkan data hasil penelitian, ditemukan adanya korelasi yang signifikan dengan kekuatan korelasi lemah antara kualitas tidur dengan kapasitas memori kerja $(p<0,05 ; r=0,281)$. Hal ini menunjukkan bahwa semakin baik kualitas tidur maka akan semakin tinggi skor kapasitas memori kerja. Hasil penelitian sejalan dengan penelitian yang dilakukan olehKabinani (2017) yang menunjukkan adanya hubungan bermakna 
antara kualitas tidur dan kapasitas memori kerja $(p<0,05 ; r=0.502)$, serta sejalan pula dengan penelitian Pratiaksa (2015) yang menunjukkan hasil korelasi Spearman antara kualitas tidur dan kapasitas memori kerja yaitu $(p<0,05 ; r=0.814)$. Penelitian dilakukanpada 143 orang yang berusia 13-18tahun di Adelaide (Australia Selatan) juga menemukan adanya hubungan antara kurang tidur yang dialami remaja dengan memori kerja. Remaja yang memiliki jumlah jam tidur yang tidak cukup akan berpengaruh pada kemampuan mereka untuk menyandikan, mengambil, dan menyimpan informasi. $^{7}$

Tidur memiliki fungsi salah satunya berpengaruh kesistem saraf sehingga dapat berdampak terhadap memori dan kemampuan belajar. Apabila seseorang mengalami suatu gangguan tidur maka fungsi dari memori dan kemampuan belajar tidak dapat berjalan dengan baik. ${ }^{10}$ Kurang tidur atau mengalami kualitas tidur yang buruk akan menyebabkan gangguan pada neurotransmitter di dalam otak, sehingga apabila dihubungkan dengan perkembangan memori, gangguan yang terjadi pada sistem neuronal tentu akan menyebabkan gangguan pada sistem memori kerja. $^{37}$ Memori yang baru terbentuk akan diperkuat oleh sinap-sinaps neuron dan akan diteruskan hingga ke pusat memori jangka panjang serta diintegrasikan dengan memori jangka panjang yang sudah ada sebelumnya. Hal tersebut terjadi pada saat tidur berlangsung. Sehingga proses rekonstruksi dan konsolidasi dari memori akan terganggu apabila mengalami gangguan dalam tidur. ${ }^{25}$

\section{Daftar Pustaka}

1. Potter, P.A. dan Perry, A.G., 2010. Fundamental Keperawatan. Edisi ke-7 Vol 2. Jakarta: Salemba Medika. pp. 18821998.

2. NSF, 2015. National sleep foundation recommends new sleep times. [online] Tersedia pada https://www.sleep foundation.org. [Diakses 13 Oktober 2017].

3. Gilbert, S.P., dan Weaver, C.C., 2010. Sleep quality and academic performance in university students: a wake-up call for 
college psychologists. $J$ Coll Student Psychother. 24, pp. 295-306.

4. Conway, A.R.A., Kane, M.J., dan Engle, R.W., 2003. Working memory capacity and its relation to general intelligence. TRENDS in Cognitive Science. 7, pp. 547-552.

5. Alloway, T.P., 2009. Working memory, but not IQ, predicts subsequent learning in children with learning difficulties. Eur $J$ Psychol. 25, pp. 92-98.

6. Brockmole, J.R., dan Logie, R.H., 2013. Age-related change in visual working memory. A study of 55,753 participants aged 8-75. Front Psychol. 3, pp. 12.

7. Gradisar, T., Terril, G., Johnston, A., dan Douglas, P., 2008. Adolescent sleep and working memory performance. Sleep Biol Rhythms. 6, pp. 146-154.

8. Liu, X., Zhao, Z.M., Jia, C.P., dan Buysee, D.J.M., 2008. Sleep pattern and problem among chinese adolescents. Pediatrics. pp. 1167-1172.

9. Deshinta, 2009. Hubungan kualitas tidur dengan tekanan darah pada remajausia 15-
17 tahun di SMA Negeri 1 Tanjung Morawa. Skripsi. Sumatera Utara: Universitas Sumatera Utara.

10. Pratiaksa, A., 2015. Hubungan kualitas tidur dengan kapasitas memori kerja pada siswa sekolah menengah atas. Skripsi. Surakarta: Universitas Sebelas Maret.

11. Oberauer, K., Sub, H.M., Schulze, R., Wilhelm, O., Wittmann, W.W., 2000. Working memory capacity - facets of a cognitive ability construct. Personality Individ Differ. 29, pp. 1017-1045.

12. Friedman, NP., dan Miyake, A., 2005. Comparison of four scoring methods for the reading span test. Behav Res Methods. 37, pp. 581-590.

13. Nursalam, Apriani, N.K., Has, E.M.M., dan Efendi, F., 2014. Sleep hygiene behavior among Balinese adolescent. $J$ Nurs Ed Practice. 4, pp. 155-160.

14. NAHIC, 2014. Sleep Deprivation in Adolescents and Young Adults. [online] Tersedia pada http://nahic.ucsf.edu. [Diakses 14 Agustus 2018]. 
15. aposky, A. D., Bass, J., Kohsaka, A., dan Turek, F. W., 2008. Sleep and circadian rhythms: key components in the regulation of energy metabolism. FEBS Lett. 582, pp. 142-151.

16. Luthfi, B.M., Azmi, S., dan Erkadius, E., 2017. Hubungan kualitas tidur dengan tekanan darah pada pelajar kelas 2 SMA Negeri 10 Padang. J Kes Andalas. 6, pp. 318-323.

17. Wahyurin, I.S., 2015. Hubungan kualitas tidur dengan konsentrasi belajar pada remaja di Yogyakarta. Skripsi.Yogyakarta: Program Studi Kesehatan Fakultas Kedokteran UGM.

18. Kabinani, T.S., 2017. Hubungan kualitas tidur dengan kapasitas memori kerja mahasiswa fakultas kedokteran universitas kristen krida wacana tahun akademik 2016/2017. Skripsi. Jakarta: Universitas Kristen Krida Wacana.

19. Nilifda, H., Nadjmir., dan Hardisman., 2016. Hubungan kualitas tidur dengan prestasi akademik mahasiswa program studi pendidikan dokter angkatan 2010 FK Universitas Andalas. J Kes Andalas. 5, pp. 243-249.

20. Kahn, A., Franco, P., Groswasser, J., dan Scaillet, S., 2004. Sleep characteristics and sleep deprivation in infants, children and adolescence. WHO Technical Meeting on Sleep and Health. pp. 22-24.

21. Fatima, Y., Suhail, A.R.,Doi, M.B.B.S., Jake, M.,Najman, danMamun, A.A., 2016. Exploring gender difference in sleepquality of youngadults: findings from a largepopulationstudy. Clin Med Res. 14, pp. $138-144$.

22. Santiago, L.C.S., Batista, R.M.F., Lyra1, M.J., Farah, B.Q., Pedrosa, R.P., Falcã, A.P.S.T., Araújo, R.C., dan Santos, M.A.M., 2017. The role played by gender and age on poor sleep quality among institutionalized adolescents. Sleep Breath. 21, pp. 197-202.

23. Orff, H.J., Meliska, C., Martinez, L., dan Parry, B., 2014. The influence of sex and 
gonadal hormones on sleep disorders.

Chrono Physiol Ther. 4, pp. 15-25.

24. Baker, S.S., dan Driver, H.S., 2007. Circadian rhythms, sleep and the menstrual cycle. Sleep Med. 8, pp. 613622.

25. Diekelmann, S.,dan Born, J., 2010. The memory function of sleep. Nat Rev Neurosci. 11, pp, 114-126.

26. Curcio, G., Ferrara, M., dan Gennaroa, L.D., 2006. Sleep loss, learning capacity and academic performance. Sleep Med Rev. 10, pp. 323-337.

27. Dehn, M..J., 2008. Working memory and academic learning, assessment and intervention. Canada: John Wiley \& Sons, Inc. pp. 2-4; 57-58; 64-65; 92-95.

28. Autin, F., dan Croizet, J.C. 2012. Improving working memory efficiency by reframing metacognitive interpreta-tion of task difficulty. J Exp Psychol. 141, pp.610-

618.
29. Baddeley, A., 2003. Working memory and language: An overview. J Commun Disord. 36 , pp. $189-208$.

30. Kaufman, S.B., 2007. Sex differences in mental rotation and spatial visualization ability: can they be accounted for by differences in working memory capacity? Intelligence. 35, pp. 211-223.

31. Lejbak, L., Crossley, M., Vrbancic, M., 2011. A male advantage for spatial and object but not verbal working memory using the n-back task. Brain Cogn. 76, pp. 191-196.

32. Lynn, R., dan Irwing, P., 2008. Sex differences in mental arithmetic, digit span, and $\mathrm{g}$ as defined as working memory capacity. Intelligence. 36, pp. 226-235

33. Masters, M.S., dan Sanders, B., 1993. Is the gender difference in mental rotation disappearing?. Behav Genet. 23, pp. 337341.

34. Nordvik, H., dan Amponsah, B., 1998. Gender differences in spatial abilities and spatial activity among university students 
in an egalitarian educational system. Sex Roles. 38, pp. 1009-1023.

35. Bae, Y., Choy, S., Geddes, C., Sable, J., dan Snyder, T., 2000. Trends in Education Equity of Girls and Women. Washington DC: U.S. Government Printing Office. pp. 76-77.
36. Hedges, L.V., dan Nowell, A., 1995. Sex differences in mental scores, variability, and numbers of high-scoring individuals. Science. 269, pp. 41-45.

37. Colten, H.R. dan Altevogt, B.M., 2006. Sleep disorders and sleep deprivation: an unmet public health problem. Washington:

National Academies. pp. 33- 